\title{
The Neuroleptic Malignant Syndrome: Do we Know Enough?
}

Ali Hassan M. Ali, MD

Thomas Jefferson University Hospital

Follow this and additional works at: https://jdc.jefferson.edu/jeffjpsychiatry

Part of the Psychiatry Commons

Let us know how access to this document benefits you

\section{Recommended Citation}

Ali, MD, Ali Hassan M. (1985) "The Neuroleptic Malignant Syndrome: Do we Know Enough?," Jefferson Journal of Psychiatry. Vol. 3 : Iss. 2 , Article 8.

DOI: https://doi.org/10.29046/JJP.003.2.004

Available at: https://jdc.jefferson.edu/jeffjpsychiatry/vol3/iss2/8

This Article is brought to you for free and open access by the Jefferson Digital Commons. The Jefferson Digital Commons is a service of Thomas Jefferson University's Center for Teaching and Learning (CTL). The Commons is a showcase for Jefferson books and journals, peer-reviewed scholarly publications, unique historical collections from the University archives, and teaching tools. The Jefferson Digital Commons allows researchers and interested readers anywhere in the world to learn about and keep up to date with Jefferson scholarship. This article has been accepted for inclusion in Jefferson Journal of Psychiatry by an authorized administrator of the Jefferson Digital Commons. For more information, please contact: JeffersonDigitalCommons@jefferson.edu. 


\title{
THE NEUROLEPTIC MALIGNANT SYNDROME: DO WE KNOW ENOUGH?
}

\author{
ALI HASSAN M. ALI, M.D.
}

The Neuroleptic Malignant Syndrome (NMS) is a potentially grave adverse reaction to oral or parenteral neuroleptic therapy that may be an underdiagnosed and easily overlooked clinical problem. NMS is characterized by hyperthermia, hypertension, diaphoresis, muscular rigidity, and altered mentation. There is currently no way of predicting which patients will develop NMS, although its incidence may be higher in patients who are unresponsive to usually effective dosages of neuroleptics (1).

NMS was first described in the French literature by Delay and Deniker in 1960 (2). They reported five cases among several hundred patients who were treated with haloperidol (Haldol ${ }^{\circledR}$ ), suggesting an incidence of approximately $0.5-1.0 \%$.

NMS typically occurs following the use of high potency neuroleptics in therapeutic dosages. The characteristic features of NMS have also been reported to occur following the use of neuroleptics in combination with lithium carbonate, during sedative-hypnotic withdrawal states, and following the use of MAO inhibitor-tricyclic antidepressant $(2,3)$. Of the four cases we reported, two were attributable to fluphenazine (Prolixin ${ }^{\circledR}$ ), one to haloperidol, and one to thiothixene (Navane ${ }^{\circledR}$ ).

The relationship between NMS and clinically similar hyperthermic reactions is unclear at this time. NMS may represent the neuroleptic-induced subtype of a more generalized syndrome that can be caused by a variety of pharmacologic agents in susceptible individuals. If so, the question arises as to why certain patients who receive therapeutic dosages of neuroleptics are more susceptible to NMS than others.

Itoh and associates have noted that prior to the onset of NMS some patients have suffered from physical exhaustion and dehydration (4). Other possible etiologic factors include age, sex, and race. Among cases reported in the literature, nearly eighty percent were young males (although NMS has been reported in males and females of all ages). Race has not been reported to be a significant factor, but the four patients we reported who developed NMS were all of African descent. This group included three males and one female with a mean age of 36.8 years.

The etiology of NMS may be related to neuroleptic-induced alteration of central neuroregulatory mechanisms (2). Neuroleptics are known to block dopamine receptors in the basal ganglia and hypothalamus. Another hypothesis is that NMS may be a muscular disorder. This theory is based on the inhibitory effect that phenothiazines can exert on the uptake of calcium by the sarcoplasmic reticulum of skeletal muscle (5); this may lead to an excessive release of these ions into the cell's cytoplasm that can cause prolonged muscle contraction. This effect is seen, however, only in suprathera-

Dr. Ali is a fourth-year resident at Eastern State Hospital in Williamsburg, Virginia. 
peutic dosages of phenothiazines, and has not been demonstrated in other classes of neuroleptics.

Once NMS begins, its signs and symptoms may develop explosively over the course of one to three days. NMS may begin from a few hours to several months after neuroleptic theory has been initiated. The cardinal feature of NMS is fever, a sign that distinguishes NMS from other adverse reactions to neuroleptics (6). Hyperthermia may be the result of blockage of dopamine receptors in the hypothalamus that control thermoregulation. Intense muscle activity may also contribute to an increase in body temperature.

Muscle rigidity in NMS has been characterized as a generalized "lead pipe" or "plastic" rigidity (2). Consciousness in NMS patients may fluctuate from an alert but dazed mutism to stupor and coma. Other features of this disorder include sialorrhea, dyskinesias, dysphasia, and autonomic nervous system involvement (manifested by severe tachycardia, labile blood pressure, profuse diaphoresis, dyspnea, and incontinence). Bizarre posturing and waxy flexibility have also been reported (6).

Recovery following appropriate treatment may be slow, and irreversible brain damage has been reported (sustained in a patient who suffered cardiac arrest during anesthesia while receiving electroconvulsive therapy (ECT) for NMS (7)). Fatalities typically occur three to thirty days after onset of NMS, usually resulting from respiratory or renal failure, cardiovascular collapse, or arrhythmias. NMS is estimated to have a mortality rate of about twenty percent (2). Mortality may be greater when hyperthermia is more severe and prolonged. One patient we reported with NMS had severe prolonged hyperthermia (around $104^{\circ}$ ) despite supportive measures and other treatment; this patient eventually developed a consumptive coagulopathy and died.

Laboratory examination may reveal several abnormalities common to NMS, and is essential in order to rule out other disorders. In NMS there may be leukocytosis ranging from 15,000 to $30,000 / \mathrm{cu} \mathrm{mm}$. Serum creatinine phosphokinase (CPK) is almost always markedly elevated, having been reported in one patient to be 15,400 I.U. $(2,8)$.

Prior to establishing the diagnosis of NMS and initiating appropriate treatment, many other disorders must be excluded. The differential diagnosis of NMS must include the following.

1) Other known causes of CPK elevation, including damage or injury to muscle such as may occur in strokes, convulsions, myocardial infarction, trauma, multiple intramuscular injections, and muscular dystrophy. Specific isoenzyme assays may help to differentiate these conditions (9).

2) Idiopathic malignant hyperthermia $(M H)$, an autosomal dominant disorder seen during or after general anesthesia, especially following the use of inhalational anesthetics or depolarizing muscle relaxants. Indeed some reports suggest that cases of NMS resulting from preoperative use of neuroleptics may have been misdiagnosed as $\mathrm{MH}(2,10)$. NMS and $\mathrm{MH}$ differ in ways besides having separate triggering agents. Curare does not alleviate rigidity associated with $\mathrm{MH}$, but in one patient with NMS it led to flacidity and diminished hyperpyrex- 
ia. Mortality from $\mathrm{MH}$ approaches seventy percent, but is less than twenty-five percent in NMS. Mild muscle enzyme elevations persist in most patients with $\mathrm{MH}$, but are normal before and after NMS (10).

3) Acute lethal catatonia, perhaps the most difficult condition to distinguish from NMS on a clinical basis (6). In the early literature, acute lethal catatonia was described as beginning with psychosis and intense motor excitement, followed by clouding of consciousness, cyanosis, marked temperature elevations, and a drop in blood pressure. Treatment of this disorder includes aggressive supportive care, adrenal cortical extract, neuroleptics, and ECT.

4) Drug-induced hyperthermia and heat stroke, an example of which is anticholinergic intoxication, which may result from various medications and is known to cause impairment of sweating mechanisms, resulting in hyperpyrexia. Unlike NMS, however, muscular rigidity is an uncommon finding in heat stroke.

5) Infections of the central nervous system, especially viral encephalitis, must be ruled out $(2,11)$. Acute viral encephalitis may present as an acute febrile state with evidence of meningeal involvement, as well as the following signs and symptoms: convulsions, confusion, stupor, coma, aphasia, mutism, hemiparesis, positive Babinski signs, involuntary movements, ataxia, myoclonic jerks, nystagmus, ocular palsies, and facial weakness. The diagnosis of viral encephalitis depends on examination of the cerebrospinal fluid (CSF), which typically reveals mononuclear and lymphocytic pleocytosis, a small increase in CSF protein, normal CSF glucose, and negative smears and cultures (12).

6) Collagen-vascular and neoplastic lesions of the central nervous system, the criteria for the diagnosis of which should be based on the tempo of the clinical syndrome, evidence of focal brain disease, the clinical setting, and appropriate laboratory investigations.

7) Severe extrapyramidal reactions, which include Parkinsonism, muscle spasms, dystonias, dyskinesias, akathesia, and tardive dyskinesia (11).

8) Other causes of rigidity, including decerebrate rigidity, hysterical rigidity, Stiff Man Syndrome, tetanus rigidity, and strychnine rigidity (2).

9) Other possible disorders, include akinetic mutism, encephalitis lethargica, and locked-in syndrome (2.)

Measurement of serum CPK would seem to be the best monitor of NMS. Serum CPK is not usually elevated in cases of fever alone and is usually higher in NMS than it is in cases of extrapyramidal reactions, catatonic states, idiopathic malignant hyperthermia, or the acute organic brain syndromes mentioned above (11).

Treatment of NMS is predicated on early recognition of its signs and symptoms. Every patient who is being treated with intramuscular neuroleptic medication should be monitored hourly for changes in vital signs and early evidence of extrapyramidal reactions or central nervous system toxicity. Whenever a patient does not respond to usually effective dosages of an intramuscular neuroleptic, he or she should be considered refractory to treatment and another modality substituted $(1,13)$.

Once the diagnosis of NMS is made, the neuroleptic being used must be 
discontinued immediately and supportive measures instituted. Supportive care should include treatment in an intensive care setting with monitoring of respiratory, cardiovascular, and renal systems. Fluid and electrolyte balance must be closely watched. Ice packs or alcohol sponges may be useful in lowering the body temperature $(1,13)$.

Promising results have been reported following the use of bromocriptine (Parlodel $\left.{ }^{\circledR}\right)$, now considered a novel treatment for NMS $(11,13)$. Dramatic improvement has been reported after its use in small dosages from 15 to $30 \mathrm{mg}$. per day. As a dopamine agonist bromocriptine may act to reverse the effects of neuroleptic medication in the central nervous system, it has been proven to lower body temperature and lessen muscle rigidity and akathisia. One might expect that because it is a dopamine agonist that bromocriptine might exacerbate psychosis. Moreover, while bromocriptine is a recognized agent for the treatment of Parkinson's disease, its use in drug-induced Parkinsonism has not yet been approved (14).

Amantadine (Symmetrel ${ }^{\circledR}$ ) is another dopamine agonist that has been reported to be successful in treating the symptoms of NMS (13). Dosages averaging $200 \mathrm{mg}$. daily have been reported to effect rapid improvement in NMS within several days. Again, because amatadine is a dopamine agonist, some worsening of psychosis might be expected.

Some authors have claimed success using dantrolene sodium (Dantrium ${ }^{\circledR}$ ), a direct-acting muscle relaxant that has also been shown to be effective in $\mathrm{MH}(10,13)$. Dantrolene acts by inhibiting the release of calcium ions from skeletal muscle, thereby ameliorating rigidity and helping to reduce body temperature. It remains unclear, however, whether favorable results may be attributable to dantrolene alone, since in most cases its use has been associated with concomitant discontinuation of neuroleptics. Recommended dosages for dantrolene have been from 200 to $300 \mathrm{mg}$. daily.

Still other authors have claimed remarkable success, especially in rapidly deteriorating patients when other modalities have failed, using electroconvulsive therapy (6). Improvement in the symptoms of NMS, including a marked reduction in body temperature, is felt to result from an increase in dopamine turnover in the brain. ECT may be particularly useful in the treatment of catatonia accompanied by fever.

\section{CASE REPORT}

Mr. S. was a thirty-three-year-old black male who was received from the city jail in handcuffs. Upon initial evaluation he was noted to be extremely agitated, irritable, restless, confused, and paranoid. He had a long history of manic episodes that were apparently precipitated by stress and alcohol abuse.

$\mathrm{Mr}$. S. was initially treated with thiothixene, $10 \mathrm{mg}$. every four hours times four dosages, then $10 \mathrm{mg}$. every six hours times eight dosages. All dosages were administered intramuscularly. Twenty-four hours after his initial injection, $\mathrm{Mr}$. S. began to sweat profusely, refused to eat, became lethargic and demonstrated marked akathisia and rigidity. His temperature, initially $98.4^{\circ}$, rose to $101.2^{\circ}$. His blood pressure was $170 / 95 \mathrm{mg} \mathrm{Hg}$. His pulse was 122 per minute. Subsequently the patient became drowsy and was transferred to the intensive care unit, where supportive measures were 
instituted. Mr. S. was begun on bromocriptine, $5 \mathrm{mg}$. three times daily, and diazepam (Valium $\left.{ }^{\circledR}\right), 10 \mathrm{mg}$. three times daily.

Four hours after Mr. S. received his first dose of bromocriptine, improvements were noted in his rigidity, akathisisa, and sensorium. His blood pressure and temperature returned to normal within twenty-four hours. His serum CPK level, initially 1553 IU, and white blood cell count, initially $16,400 / \mathrm{cu} \mathrm{mm}$, also returned to within normal limits within five days after treatment had begun. Mr. S. was gradually weaned from medication and subsequently discharged two weeks later.

\section{DISCUSSION}

An increasing number of physicians are learning about NMS, a potentially lethal condition that may be underdiagnosed. As time goes on a greater number of neuroleptics are being implicated in the etiology of NMS. The picture is clouded, however, by the number of patients who develop NMS who are concomitantly receiving other medications (including other neuroleptics). Hopefully, the increase in physicians' awareness of this disorder and promising new modes of treatment will combine to minimize the morbidity and mortality that may result from NMS.

\section{REFERENCES}

1. Frank A: Malignant syndrome. Int Dr Th Nwsl 15, 1980

2. Caroff S: The neuroleptic malignant syndrome. J Clin Psych 41: 79-83, 1980

3. Tupin JP, Schuller AB: Lithium and haloperidol incompatibility reviewed. Psych J Univ Ott 3: $245-251,1978$

4. Itoh H, Ohtsuka N, Ogita K: Malignant neuroleptic syndrome. Folia Psych et Neur JPN 31: 565-576, 1977

5. Rosenberg H: malignant hyperthermia syndrome. Anesth Anal 3: 466, 1977

6. Jessee SC, Anderson GF: ECT in the neuroleptic malignant syndrome. J Clin Psych 44: 186-188, 1983

7. Regestein G, Alpert J, Reich P: Sudden catatonic stupor with disastrous outcome. JAMA 238: 618-620, 1977

8. Fabre $\mathrm{S}$, Gervais $\mathrm{C}$, Manue $\mathrm{C}$ : Le syndrome malin des neuroleptiques a propos de 7 cas. Encephale 3: 321-326, 1977

9. Mann SC, Boger WP: Psychotropic drugs, summer heat, and humidity, and hyperpyrexia: a danger restated. Am J Psych 135: 1097-1100, 1978

10. Henderson VW: Questions about dantrolene for NMS. Am J Psych 140: 137-138, 1983

11. Mueller PS, Vester JW: The NMS—successful treatment with bromocriptine. JAMA 249: 386-388, 1983

12. Kakulas BA, Adams RD: Viral infections of the nervous system, in Harrison's Principles of Internal Medicine. Edited by Thorn GW, Adams RD, Braunwald E, Isselbacker KJ, Petersdorf RB. McGraw-Hill, New York, 1980

13. Frank A: The NMS—new therapies. Int Dr Th Nwsl 18, 1983

14. Parlodel ${ }^{\circledR}$ (bromocriptine mesylate), in Physician's Desk Reference, 38th Edition. Oradell, Medical Economics, 1984 